\title{
Influence of Fruit Ripening on the Total and Individual Capsaicinoids and Capsiate Content in Naga Jolokia Peppers (Capsicum chinense Jacq.)
}

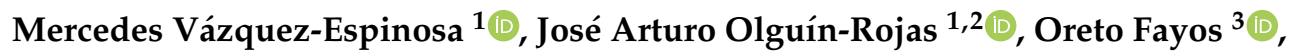 \\ Ana V. González-de-Peredo ${ }^{1}$ (D) , Estrella Espada-Bellido ${ }^{1}(\mathbb{D})$, Marta Ferreiro-González ${ }^{1}(\mathbb{D})$, \\ Carmelo G. Barroso ${ }^{1}$, Gerardo F. Barbero ${ }^{1, * \mathbb{D}}$, Ana Garcés-Claver ${ }^{3}$ (D) and Miguel Palma ${ }^{1}$ \\ 1 Department of Analytical Chemistry, Faculty of Sciences, University of Cadiz, \\ Agrifood Campus of Internacional Excellence (ceiA3), IVAGRO, 11510 Puerto Real, Cadiz, Spain; \\ mercedes.vazquez@uca.es (M.V.-E.); arturo.olguinrojas@alum.uca.es (J.A.O.-R.); \\ ana.velascogope@uca.es (A.V.G.-d.-P.); estrella.espada@uca.es (E.E.-B.); marta.ferreiro@uca.es (M.F.-G.); \\ carmelo.garcia@uca.es (C.G.B.); miguel.palma@uca.es (M.P.) \\ 2 Promotora Técnica Industrial S. A. de C. V., Calle 56 Sur, Mza 1, CIVAC, Jiutepec 62578, Morelos, Mexico \\ 3 Centro de Investigación y Tecnología Agroalimentaria de Aragón, Instituto Agroalimentario de Aragón-IA2, \\ CITA-Universidad de Zaragoza, Avda. Montañana 930, 50059 Zaragoza, Spain; ofayos@cita-aragon.es (O.F.); \\ agarces@cita-aragon.es (A.G.-C.) \\ * Correspondence: gerardo.fernandez@uca.es; Tel.: +34-956-016355; Fax: +34-956-016460
}

Received: 30 December 2019; Accepted: 5 February 2020; Published: 8 February 2020

\begin{abstract}
Naga Jolokia" (Capsicum chinense Jacq.) is a hot pepper variety native to India which has received the attention of the global scientific community due to its high capsaicinoid concentration. The present study evaluated the influence of fruit ripening on the total and individual capsaicinoids, as well as capsiate content. The aim was to determine the optimal moment to harvest the peppers depending on their pungent properties. Ultrasound-assisted extraction (UAE) using methanol as the extraction solvent and reverse-phase ultra-high-performance liquid chromatography (UHPLC-photodiode array (PDA)) were employed. Capsaicinoids gradually accumulated in the peppers from the moment they started growing until they reached a maximum concentration $\left(7.99 \pm 0.11 \mathrm{mg} \mathrm{g}^{-1}\right.$ of fresh weight $\left.(\mathrm{FW})\right)$ at 33 days postanthesis (dpa). For this reason, based on its content of pungent compounds, as it is one of the main attributes of this variety, the optimal time for collection would be on day 33. From then on, there was a sharp decrease $(96.35 \%$ of the total concentration) due to the peroxidase enzymes. The evolution of the principal capsaicinoids in "Naga Jolokia" peppers had a different behavior with respect to literature reports. After this investigation, these changes in content can be attributed to each pepper genotype. Capsiate content reached it maximum value at $19 \mathrm{dpa}\left(0.27 \pm 0.01 \mathrm{mg} \mathrm{g}^{-1}\right.$ of FW $)$. Then, there was a gradual drop due to the activities of different peroxidases. Given the important biological activity of capsaicinoids and capsinoids, the information described here allows for determining the ideal time to harvest "Naga Jolokia" peppers.
\end{abstract}

Keywords: Naga Jolokia; Capsicum chinense; capsaicinoids; capsiate; pepper fruit development; ultrasound-assisted extraction

\section{Introduction}

For several decades, the association between nutrition and health has been gaining popularity, and therefore, increased importance has been given to diets based on antioxidant-rich vegetables and fruits [1]. Pepper (Capsicum spp.) is one of the most valued vegetables because of its rich content 
in bioactive compounds, vitamins, and also for its high antioxidant properties. The genus Capsicum belongs to the Solanaceae family and it is native to tropical and humid areas in Central and South America. It is widely used worldwide as a culinary condiment for its flavor, aroma, and color, and it is also commercialized as a fresh product, dry crushed pepper, paprika oleoresin, or pepper paste [2,3]. The consumption of red peppers (chili peppers) is generally associated with spicy, burning, or pungent sensations, colloquially referred to as "hot flavor". The pungency of this vegetable is caused by two groups of chemical compounds known as capsaicinoids and capsinoids [4].

Capsaicinoids are nonvolatile alkaloids, which are chemically acid amides of $\mathrm{C}_{9}-\mathrm{C}_{11}$ branched-chain fatty acids and vanillylamines. The main compounds are capsaicin (C) (trans-8-methyl- $N$-vanillyl-6-nonenamide) and dihydrocapsaicin (DHC) (8-methyl- $N$-vanillylnonanamide), which generally represent around $77 \%-98 \%$ of the total capsaicinoid content. Some other related compounds, such as nordihydrocapsaicin (n-DHC), homocapsaicin (h-C), or homodihydrocapsaicin (h-DHC), are also present in minor amounts among the over 20 other reported compounds [5,6]. These compounds have exhibited numerous biological properties of pharmacological relevance, such as antioxidant [7], anti-inflammatory [8], analgesic [9], antimicrobial [10], and anticarcinogenic [11] activities. Moreover, they are related to an increase in body energy and a decrease in both fat and cholesterol accumulation, which leads to a reduction in cardiovascular diseases, diabetes, or strokes [12]. One of its negative aspects is that high doses or long-term exposure have a detrimental effect on the gastric mucosa and, ultimately, on health. Epidemiological studies have revealed that the consumption of chili peppers in large amounts causes an increased risk of gastric cancer. In addition, some capsaicin metabolites may attack the DNA and trigger mutagenicity and malignant transformation [13].

Capsinoids were identified in the late 1980s in the low-pungent cultivar CH-19 Sweet (Capsicum annuum L.) [14]. Capsinoids exhibit similar health-promoting properties as capsaicinoids, although they are less irritating, nonspicy, and contain tastier compounds (its pungency is assessed to be about 1000 times lower than that of capsaicinoids), so they can be used at higher concentrations in agrifood applications [15]. The differences in the perception of pungency are related to the receptor vanilloid type-1 (TRPV1). This receptor is responsible for the burning sensation. Capsaicinoids activate TRPV1 receptors on the consumer's tongue, while capsinoids have the capacity to activate them in the gut with a similar physiological effect. This difference in the activation site allows the absence of burning sensation in the capsinoids [16]. They have a very similar chemical structure, with the exception of their central bond, being vanillic alcohol esters with fatty acid chains similar to those of capsaicinoids. This structural difference could be the reason for the lower stability of capsinoids. To date, three different capsinoids have been isolated from the fruits of several pepper varieties (capsiate (CTE), dihydrocapsiate (DHCTE), and nordihydrocapsiate (n-DHCTE)) [17].

Capsaicinoids are naturally synthesized in the placenta of peppers by enzymatic condensation of vanillylamine with different length fatty acid chains $C_{9}-C_{11}$ [18]. Capsinoids are natural compounds found in different varieties of sweet peppers. Their maximum interest lies in the demonstrated biological activity that they exhibit. That is the reason why the study of synthesis procedures of both natural and synthetic capsinoids, with similar properties to natural ones, is of great interest because of the difficulty in isolating these compounds. Therefore, the procedure for the chemical synthesis of this type of compound has been patented and published. It consists of four high-performance selective reactions: protection of the vanillin hydroxyl group, carbonyl reduction and subsequent esterification, and deprotection of the protected capsinoids $[19,20]$.

Peppers are harvested and consumed at different ripening stages, from immature green to fully ripe. Throughout their maturation, numerous biochemical, physiological, and structural changes take place. The changes that occur during the maturation stage do not only have well-known agronomical implications (e.g., taste, color, size, postharvesting properties, etc.) but are also relevant to determine the harvested fruit application and quality [1]. For this reason, the accumulation of antioxidant compounds at different stages of fruit development is essential. The production and concentration of 
these compounds is influenced by both genetic and environmental factors. To mention some of them, the species and cultivars of Capsicum, the growth conditions and the cultivation techniques [21,22], the availability of water [23], the contribution of mineral supplements to the crop, light conditions, high temperatures, or plant infections $[24,25]$ also may contribute to the concentration of capsaicinoids. Several studies have been carried out to elucidate the process of synthesis and accumulation of capsaicinoids over the maturation period [26,27]. It has been observed that these compounds begin to accumulate from the early stages of fruit development and continue to increase their content during ripening until a maximum concentration is reached, which is usually after 40-60 days postanthesis (dpa). Beyond this point there is a rapid turnaround in the trend due to their degradation by the action of some specific enzymes called peroxidases. The first report of capsaicin oxidation by a peroxidase enzyme was performed by Boersch et al. [28]. After that, Bernal et al. reported the first oxidation data of $\mathrm{C}$ and DHC by a pepper peroxidase [29]. Classical secretory plant peroxidases (class III Prx) are heme-containing glycoproteins able to oxidize different substrates using hydrogen peroxide as an electron donor. These are a type of basic peroxidases. Peroxidases may be directly related to capsaicinoid metabolism since the vanillyl moiety of capsaicin is easily oxidized by this enzyme. The oxidation of capsaicinoids by Capsicum peroxidase is strictly dependent on the presence of $\mathrm{H}_{2} \mathrm{O}_{2}$. Lema et al. proved that the basic peroxides of peppers are also responsible for the degradation of capsinoids [30].

The present study focused on the pepper variety known as "Naga Jolokia". It is native to northeastern regions of India and is mainly cultivated in Bangladesh and the Indian States of Assam, Nagaland, and Manipur [31]. This pepper is also of great commercial importance in Brazil. "Naga Jolokia" has received the attention of the global scientific community because of its extremely high pungency and unique aroma. In 2010, it was recognized by the Guinness Book of Records as the hottest chili in the world, reaching more than 1 million Scoville Heat Units (SHUs) [32]. It is used as a spice in both fresh and dried form or eaten raw along with the staple food. Because of its refreshing aroma, palatability, and medicinal properties, people have been using it for pickle preparation; to flavor curries; or as a popular remedy for different ailments such as gastritis, arthritis, or chronic indigestion problems. It has also been used to tone up body muscles after heavy workout sessions, whereas hot infusions are used for toothache or muscle pain [33].

Ultrasound-assisted extraction (UAE), a simple and inexpensive method, was used since it improves extraction efficiency by disrupting cell walls, reducing particle size, and improving mass transfer thanks to the cavitation effect [34]. Ultra-high-performance liquid chromatography working in reverse-phase (rp-UHPLC) was employed for its separation and quantification. The rp-HPLC technique is the most commonly used for the analysis of these compounds in fresh pepper [26]. However, rp-UHPLC has recently been proved to be more effective and faster, which makes it a feasible alternative for the analysis of such compounds of interest [35,36].

In order to minimize production costs by achieving the desirable high levels of pungency in the peppers, it is necessary to determine the optimum moment to harvest the peppers so that they present their maximum concentration of capsaicinoids and capsinoids, thus giving greater added value to the product. Therefore, the final objective of this work was to evaluate the accumulation of total and individual capsaicinoids and capsinoids during the ripening stages of "Naga Jolokia" peppers in order to determine the optimum moment to harvest them.

\section{Materials and Methods}

\subsection{Chemicals}

The methanol (99.9\%) from Panreac Química S.L.U. (Castellar del Vallés, Barcelona, Spain) used for both extraction and chromatographic identification, the acetonitrile (99.9\%) from Panreac Química S.L.U. (Castellar del Vallés, Barcelona, Spain) used for chromatographic separation, and the glacial acetic acid (99\%) from Merck (Darmstadt, Germany) were HPLC grade. The water was obtained from a 
Milli-Q water deionization system (Millipore, Bedford, MA, USA). The reference standards of capsaicin $(97 \%)$ and dihydrocapsaicin (90\%) were acquired from Sigma-Aldrich Chemical Co. (St. Louis, MO, USA). Capsiate standard was synthesized following the method described by Barbero et al. [19].

\subsection{Plant Material}

"Naga Jolokia" (Capsicum chinense Jacq.) seeds were supplied by the AgriFood Research and Technology Center of Aragon (CITA), located in Zaragoza, Spain. The seeds were germinated in Petri dishes until the cotyledons were developed. Then, each plantlet was placed in a Jiffy-7 pot (Clause-Tezeir Iberica, Almería, Spain). Once the plants had three true leaves (approximately 6 weeks after sowing), each Jiffy pot was transplanted into a black plastic pot (one plant per pot) of $17 \mathrm{~cm}$ in diameter. Each pot contained a substrate mixture made of Humin Substrat (Klasman-Deilmann, Geeste, Germany) (1:1:1:1, v/v) peat, sand, clay-loam, and soil, enriched with $2 \mathrm{~g}$ of a slow-release fertilizer (Osmocote 16N-4P-9K, Scotts, Tarragona, Spain), and watering by a drip irrigation system. Twenty plants of cultivar "Naga Jolokia" were grown during the spring-summer seasons (April-September 2016) under controlled conditions in a climatized glasshouse located at CITA. The average day/night temperatures over the period of the study were $24 / 14^{\circ} \mathrm{C}$ in the spring and $27 / 19^{\circ} \mathrm{C}$ in the summer.

Blooming started in mid-July until the end of September. The monitoring of the fruit development was performed by labeling and dating the flowers at anthesis to determine the fruit stage of development. "Naga Jolokia" fruits were harvested at nine stages of development: 12, 19, 26, 33, 40, 47, 54, 61, and $68 \mathrm{dpa}$.

Once the samples were harvested, peppers were grouped according to their developmental stage (by dpa). While the stem and seeds were discarded, the pericarp and placenta were ground together in an Ultra-Turrax blender to obtain a completely homogeneous sample. Finally, they were frozen at $-20{ }^{\circ} \mathrm{C}$ until further analysis.

\subsection{Ultrasound-Assisted Extraction of Capsaicinoids and Capsiate}

The extracts from the pepper samples at the different maturation stages were obtained using a UAE technique. To apply the ultrasounds, a Sonoplus probe (BANDELIN ELECTRONIC, Heinrichstraße, Berlin, Germany), which allows the control and modification of the amplitude and cycle, was used. This probe was coupled to a thermostatic bath with temperature control by means of a $7 \mathrm{~L}$ refrigerated circulator (PolyScience, Niles, IL, USA) and was submerged into a double-walled vessel that allowed the temperature of the liquid inside to be maintained. The capsaicinoids were extracted by applying a previously developed method [37], in which $1 \mathrm{~g}$ of fresh pepper sample was put in contact with $25 \mathrm{~mL}$ of methanol for $10 \mathrm{~min}$ at $50{ }^{\circ} \mathrm{C}$, using $80 \%$ of the maximum power $(200 \mathrm{~W})$ and a cycle of $0.5 \mathrm{~s}$. The extraction of the capsinoids was performed by means of our previously developed method [38], in which $15 \mathrm{~mL}$ of solvent was added to $0.5 \mathrm{~g}$ of peppers, and the sample was subjected to UAE for $2 \mathrm{~min}$ at a temperature of $5.5^{\circ} \mathrm{C}$, using $80 \%$ of the maximum power $(200 \mathrm{~W})$ and a cycle of $0.5 \mathrm{~s}$. The extracts were filtered through a $0.22 \mu \mathrm{m}$ nylon syringe filter (Membrane Solution, Dallas, TX, USA) prior to their chromatographic analysis. The extraction process was carried out in triplicate for each homogeneous sample obtained on each different ripening days. The sample was considered homogeneous since it was composed of all the peppers obtained at each ripening state. Then, the quantification of the compounds in each replicate was performed by means of UHPLC. The final result obtained would be the average of these three values.

\subsection{Capsaicinoids and Capsiate Identification}

The five principal capsaicinoids as well as the major capsinoid present in "Naga Jolokia" pepper were identified by ultra-high-performance liquid chromatography coupled to a quadrupole-time-of-flight mass spectrometer (UHPLC-Q-ToF-MS) (Xevo G2 QToF, Waters Corporation, Milford, MA, USA). This equipment consisted of a self-sampler, a quaternary and binary solvent manager, a photodiode array (PDA) detector, and an rp-C18 analytical column (Acquity UPLC BEH 
C-18, Waters, MA, USA, $2.1 \times 100 \mathrm{~mm}$ and $1.7 \mu \mathrm{m}$ particle size). A gradient method, using water as solvent $\mathrm{A}$ and methanol as solvent $\mathrm{B}$, both acidified by $0.1 \%$ formic acid, working at a flow of $0.4 \mathrm{~mL} \mathrm{~min}^{-1}$ was used. The elution gradient employed was as follows (time, \% solvent $\mathrm{B}$ ): $0 \mathrm{~min}, 0 \%$; $0.85 \mathrm{~min}, 55 \%$; $1.60 \mathrm{~min}, 55 \%$; $1.95 \mathrm{~min}, 60 \%$; $2.45 \mathrm{~min}, 63 \%$; $2.80 \mathrm{~min}, 70 \%$; $3.00 \mathrm{~min}, 70 \%$; $6.00 \mathrm{~min}$, $100 \% ; 8 \mathrm{~min}, 100 \%$. The injection volume was set to $3 \mu \mathrm{L}$ and the column temperature was adjusted at $50{ }^{\circ} \mathrm{C}$.

The analytes were determined by an electrospray source operating in positive ionization mode under the following conditions: desolvation gas flow $=850 \mathrm{~L} \mathrm{~h}^{-1}$; desolvation temperature $=500{ }^{\circ} \mathrm{C}$; cone gas flow $=10 \mathrm{~L} \mathrm{~h}^{-1}$; source temperature $=150^{\circ} \mathrm{C}$; capillary voltage $=0.7 \mathrm{eV}$; cone voltage $=20 \mathrm{~V}$; and trap collision energy $=4 \mathrm{eV}$. Full-scan mode was used $(\mathrm{m} / \mathrm{z}=100-600)$. The molecular ions $[\mathrm{M}+\mathrm{H}]^{+}$ of the compounds identified had the following $\mathrm{m} / \mathrm{z}$ ratios: nordihydrocapsaicin (n-DHC) 294, capsaicin (C) 306, dihydrocapsaicin (DHC) 308, homocapsaicin (h-C) 320, homodihydrocapsaicin (h-DHC) 322, and capsiate (CTE) 307. Additional information regarding the chromatographic and $\mathrm{m} / z$ parameters of these compounds for the UHPLC-QToF-MS method has been included in Table S1.

\subsection{Capsaicinoids and Capsiate Analysis}

Once the capsaicinoids and capsiate had been identified, the separation and quantification of these compounds were carried out by rp-UHPLC-PDA (Acquity Ultra Performance LC Class, Waters Corporation, Milford, MA, USA), since this is the technique available to our research group. This equipment consists of an ACQUITY UPLC H-Class Auto Sampler with temperature control adjusted at $15^{\circ} \mathrm{C}$, an ACQUITY UPLC Quaternary Pump System, an ACQUITY UPLC PDA Detector, and a Waters ACQUITY UPLC BEH rp-C18 column $(100 \times 2.1 \mathrm{~mm}, 1.7 \mu \mathrm{m}$ particle size $)$ set at $50{ }^{\circ} \mathrm{C}$.

A gradient method using water as solvent $A$ and acetonitrile $99.9 \%$ from Panreac Química S.L.U. (Castellar del Vallés, Barcelona, Spain) as solvent B, both acidified by means of $0.1 \%$ acetic acid, running at a flow of $0.8 \mathrm{~mL} \mathrm{~min}{ }^{-1}$ was used for the separation of capsaicinoids and capsiate. The elution gradient employed was as follows (time, \% solvent B): $0 \mathrm{~min}, 0 \%$; $0.50 \mathrm{~min}, 45 \%$; $1.60 \mathrm{~min}, 45 \%$; $1.95 \mathrm{~min}, 50 \%$; $2.45 \mathrm{~min}, 55 \%$; $2.80 \mathrm{~min}, 63 \%$; $3.00 \mathrm{~min}, 63 \%$; $4 \mathrm{~min}, 100 \% ; 6.00 \mathrm{~min}, 100 \%$. The injection volume was set at $3 \mu \mathrm{L}$ and the wavelength for ultraviolet detection was $280 \mathrm{~nm}$.

For the quantification, the calibration curves of $C\left(y=1669.70 x+36.08, R^{2}=0.9997\right)$ and DHC $\left(y=1688.31 x+29.42, R^{2}=0.9998\right)$, which are the two capsaicinoid standards that are commercially available, as well as another one of CTE $\left(y=1682.50 x-164.74, R^{2}=0.9997\right)$ were used. The detection limits ( $1.65 \mathrm{ng} \mathrm{g}^{-1}$ fresh weight (FW), $1.25 \mathrm{ng} \mathrm{g}^{-1} \mathrm{FW}$, and $3.60 \mathrm{ng} \mathrm{g}^{-1} \mathrm{FW}$ ) and quantification limits (5.50 $\mathrm{ng} \mathrm{g}^{-1} \mathrm{FW}, 4.17 \mathrm{ng} \mathrm{g}^{-1} \mathrm{FW}$, and $12.00 \mathrm{ng} \mathrm{g}^{-1} \mathrm{FW}$ ) for C, DHC, and CTE, respectively, were determined as the analytic concentration that corresponds to the standard deviation from the blank signal values $(n=10)$ plus 3 or 10 times, respectively, divided by the slope of the linear regression. Commercial standards of n-DHC, h-C, and h-DHC were not available and these compounds had to be quantified based on the calibration curve of DHC (n-DHC and h-DHC) and the calibration curve of C (h-C) given the structural similarities between these molecules and taking into account their molecular weights. Additional information regarding the chromatographic parameters of capsaicinoids and capsiate for the UHPLC-PDA method has been included in Table S2.

\subsection{Statistical Analysis}

The statistical significance of the model was evaluated by means of a Tukey's test using Statgraphic Centurion Version XVII (The Plains, Fauquier, WV, USA). MassLynx version 4.1 for identification (UHPLC-Q-ToF-MS) and Empower 3 for separation and quantification (UHPLC-PDA) software, both from Waters Corporation (Milford, MA, USA), were used to control the equipment and for the acquisition and treatment of the data. 


\section{Results and Discussion}

\subsection{Evolution of the Total Capsaicinoid Content}

The "Naga Jolokia" plants began to produce peppers during the second week in July and they were harvested on September 30th. The evolution of capsaicinoid content was monitored during the maturation of the fruits from the 12th dpa. The visual state of the peppers at the time of harvesting is shown in Table 1.

Table 1. Code and visual state of "Naga Jolokia" pepper fruits at different stages of fruit development (days postanthesis, dpa).

\begin{tabular}{cccc}
\hline Code & Fruit Sprouting & Dpa & Visual State \\
\hline M-1 & $18 / 09$ & 12 & Green color \\
M-2 & $11 / 09$ & 19 & Green color \\
M-3 & $04 / 09$ & 26 & Green color \\
M-4 & $28 / 08$ & 33 & Green color \\
M-5 & $21 / 08$ & 40 & Yellow color \\
M-6 & $14 / 08$ & 47 & Orange color \\
M-7 & $07 / 08$ & 54 & Red color \\
M-8 & $31 / 07$ & 61 & Red color \\
M-9 & $24 / 07$ & 68 & Red color/over-ripeness \\
\hline
\end{tabular}

The first step was to perform the sample extraction in each of the maturation stages by ultrasound-assisted extraction, using the conditions mentioned above with both developed methods. Subsequently, the quantification of the capsaicinoids was carried out by UHPLC-PDA to study the tendency of each of them throughout the ripening of the fruit.

Ananthan et al. [2] reported the content of capsaicinoids in different components of the cultivar "Naga Jolokia" peppers during the green, yellow, and red stages, but they did not perform a complete study over the ripening stage. Several authors have reported that the highest level of capsaicinoids in peppers is at $40 \mathrm{dpa}$, followed by a gradual degradation of these compounds due to the action of peroxidase enzymes [24,25,39]. However, during this study, it was found that "Naga Jolokia" peppers reached their maximum concentration before $40 \mathrm{dpa}$ (specifically at $33 \mathrm{dpa}$ ), and a subsequent drastic drop of about $96 \%$ took place, which has not ever been reported for any other pepper variety [3]. These differences could be attributed to genotype, growing conditions, or environmental factors.

Figure 1 shows that the total capsaicinoid content increased from 12 dpa until the maximum level was reached at $33 \mathrm{dpa}$ with a concentration of $7.99 \pm 0.11 \mathrm{mg} \mathrm{g}^{-1}$ in fresh pepper (FW). This value is similar to other $C$. chinense varieties, such as "Habanero" pepper [40,41], and is quite similar to other studies on "Bhut Jolokia" peppers [42]. Then, between 33 and $40 \mathrm{dpa}$, a very sharp decrease took place down to $0.41 \pm 0.10 \mathrm{mg} \mathrm{g}^{-1}$ of $\mathrm{FW}$, which corresponded to a $96.35 \%$ reduction in capsaicinoid content. This drastic reduction could be attributed to the action of basic peroxidases, which may have degraded the capsaicin and dihydrocapsaicin molecules [43]. This degradation of the capsaicinoids by the action of the peroxidases coincided with the change of green to red color that took place with the ripening of the peppers. 


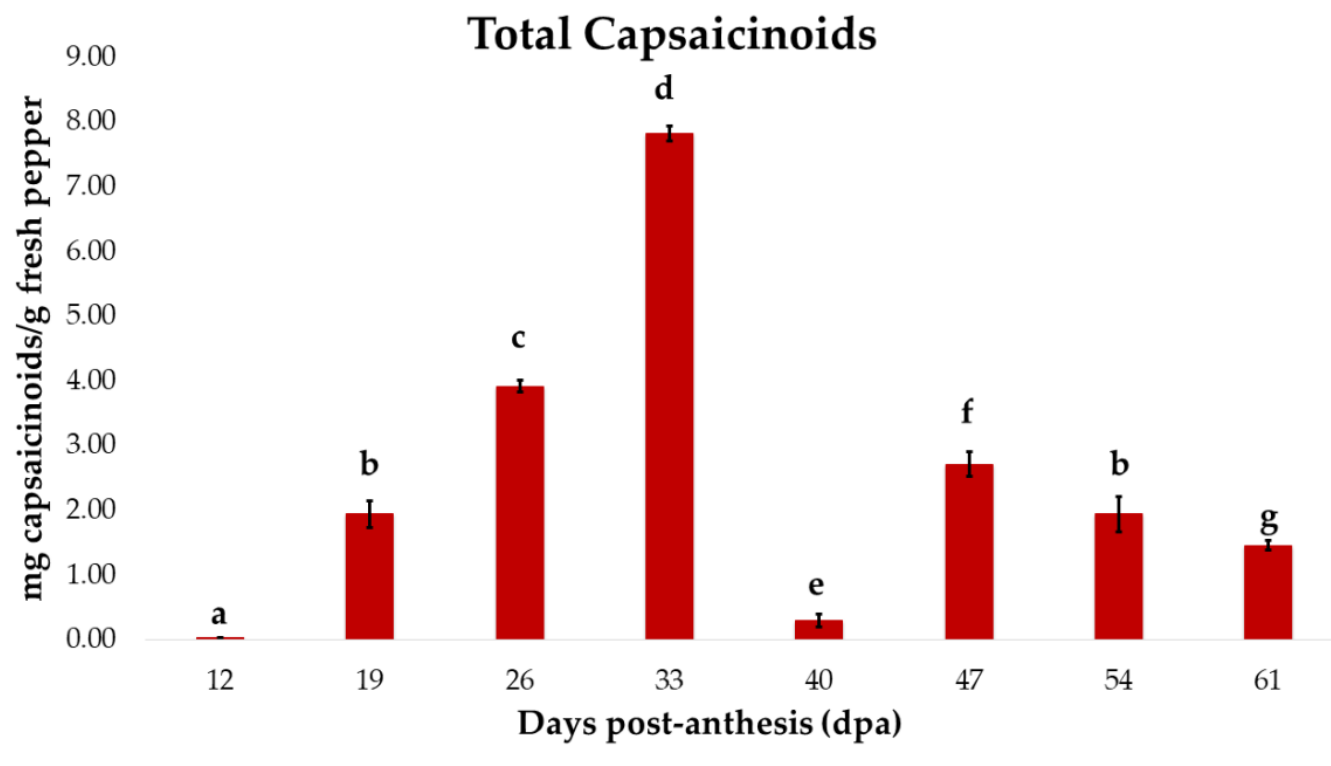

Figure 1. Evolution of total capsaicinoid content $\left(\mathrm{mg} \mathrm{g}^{-1}\right.$ of fresh weight $(\mathrm{FW})$ ) during "Naga Jolokia" pepper fruit development $(n=3)$. According to the Tukey's test, results with a $p$-value less than 0.05 were considered to be statistically different. Taking this into account, the use of different letters in this figure indicates that there is a significant difference between results depending on Tukey's test.

It should be noted that this sharp decline has not been previously observed in other pepper cultivars. Several studies have shown a considerably smaller reduction in the total amount of capsaicinoids, ranging from $30 \%$ to $65 \%$ in different pepper cultivars such as "Habanero", "Piquín", "Chile de Árbol", or "Padrón" [25,44]. Meghvansi et al. [31] presented a comparison between different locations and suggested that weather and climatic conditions may affect the pungency intensity of "Naga Jolokia" peppers. However, Olguín-Rojas et al. applied similar growing conditions to other varieties of pepper that were grown simultaneously and did not observe any sharp reduction in the total amount of capsaicinoids [45]. This may suggest that changes in content could be attributed to each pepper genotype. After the sudden drop in the total concentration of capsaicinoids, an increase took place until $47 \mathrm{dpa}$. From then on, the concentration of capsaicinoids decreased slightly and then remained practically constant until the end of the ripening process. Subsequent days of ripening were not treated as a result of the over-ripening observed in the fruit, which caused water loss and wrinkling, among other changes.

\subsection{Evolution of the Individual Content of Capsaicinoids}

The five capsaicinoids identified in "Naga Jolokia" peppers, using the UHPLC-Q-ToF-MS equipment with a PDA detector and rp-C18 analytical column, were n-DHC, C, DHC, h-C, and h-DHC. Once identified, each of them was quantified by the UHPLC equipment. Their individual concentrations ( $m g$ of capsaicinoid $\mathrm{g}^{-1}$ of FW) throughout the ripening of the fruit are represented in Figure 2. It can be seen that, like other studies [22,46], $\mathrm{C}$ was the major capsaicinoid over the entire maturation of the fruit, followed by DHC, n-DHC, h-C, and finally h-DHC in smaller amounts. This is concordant with the results from similar studies on $C$. chinense, since capsaicin is the capsaicinoid responsible for the high pungency of the fruit, followed by dihydrocapsaicin [40,47]. 


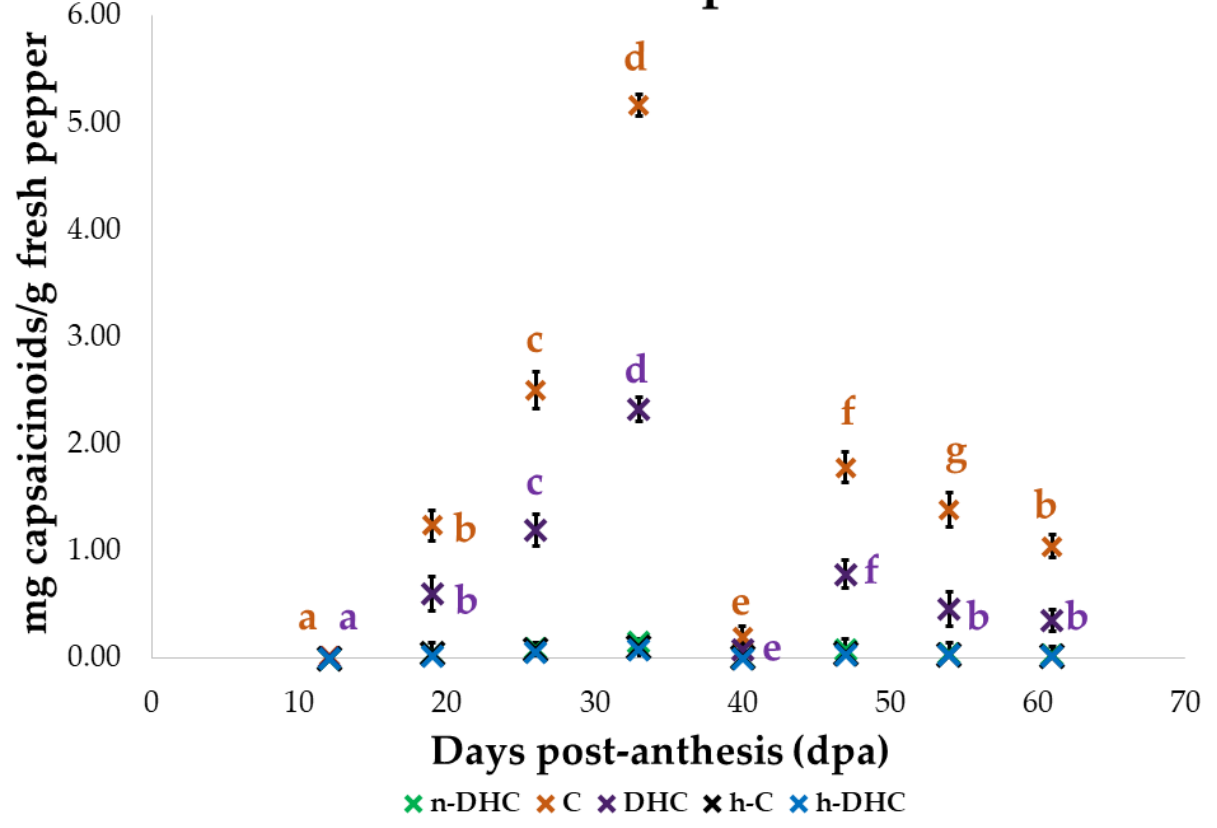

Figure 2. Evolution of individual capsaicinoid content ( $\mathrm{mg} \mathrm{g}^{-1}$ of FW) during "Naga Jolokia" pepper fruit development $(n=3)$. According to the Tukey's test, results with a $p$-value less than 0.05 were considered to be statistically different. Taking this into account, the use of different letters in this figure indicates that there is a significant difference between results depending on Tukey's test. In turn, the letters of each color refer to their respective capsaicinoid, orange for capsaicin (C) and purple for dihydrocapsaicin (DHC). Only the existence or not of a significant difference in the two major compounds has been indicated in Figure 2 for a better viewing. The results obtained for the three minor capsaicinoids (nordihydrocapsaicin (n-DHC), homocapsaicin (h-C), and homodihydrocapsaicin (h-DHC)) are shown in detail in Figure S1 with a different scale.

The evolution of total capsaicinoids was similar to the evolution of each individual capsaicinoid. In this way, the five individual capsaicinoids increased their concentration until they reached their maximum at $33 \mathrm{dpa}$. Then, the concentration of capsaicinoids drastically fell at $40 \mathrm{dpa}$. As explained above, there was a new increase until $47 \mathrm{dpa}$ and then a gradual decrease of individual capsaicinoids between 47 and 61 dpa.

Figure 3 shows the percentage patterns of the five major capsaicinoids during the ripening process. It can be observed that the increments in the percentage of capsaicin corresponded to decreases in the percentage of dihydrocapsaicin and vice versa. In addition, it can also be noticed that capsaicin slightly increased its concentration throughout maturation, while dihydrocapsaicin's concentration decreased slightly. These two major capsaicinoids may represent between $93 \%$ and $96 \%$ of the total capsaicinoid content (approximately $70 \%$ and $25 \%$ of capsaicin and dihydrocapsaicin, respectively). Their concentration depended on the fruit ripening stage, being therefore the two main capsaicinoids found in this pepper variety. The other three minor capsaicinoids (n-DHC, h-C, and h-DHC) had a similar behavior, since they were present in similar percentages that ranged between $0 \%$ and $3 \%$ for each of them and also varied according to the ripeness of the fruit. 


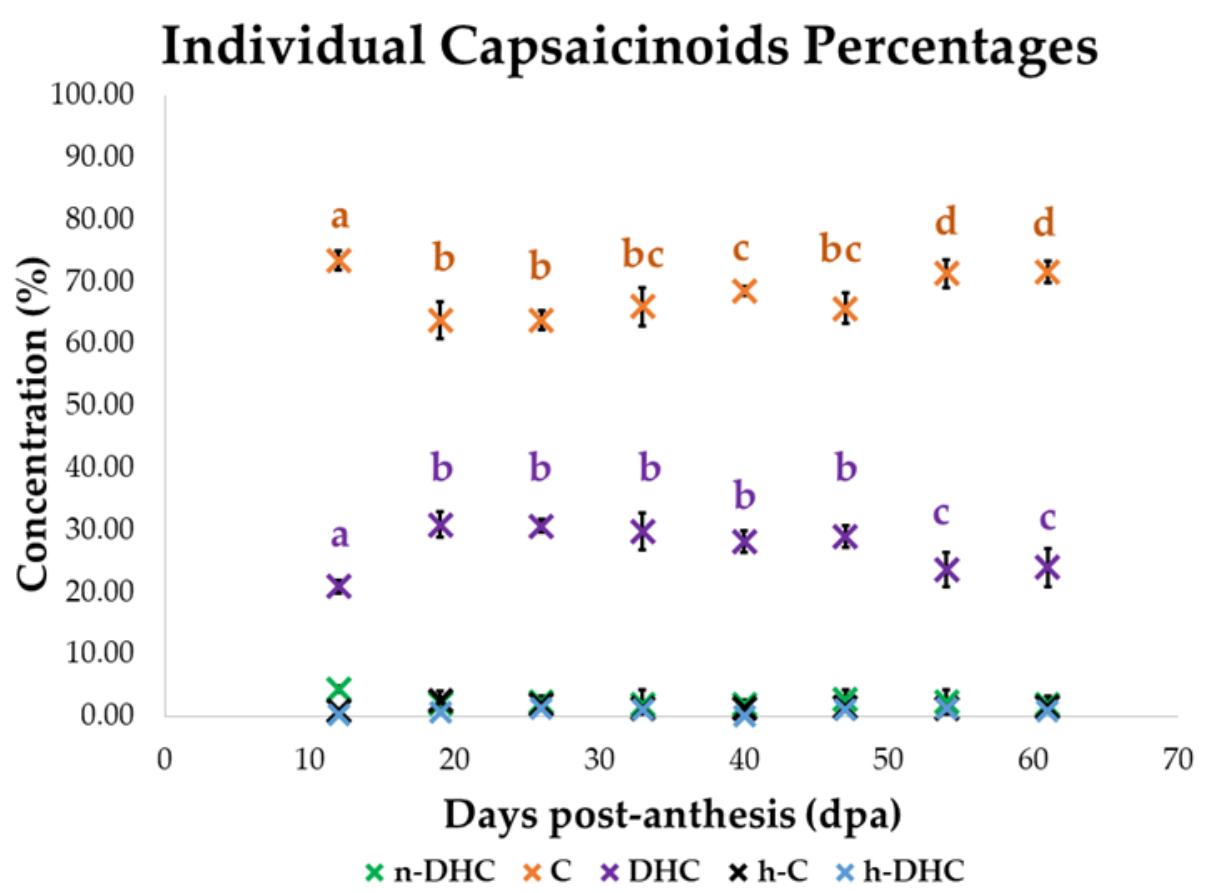

Figure 3. Evolution of individual capsaicinoid percentages during "Naga Jolokia" pepper fruit development $(n=3)$. According to the Tukey's test, results with a $p$-value less than 0.05 were considered to be statistically different. Taking this into account, the use of different letters in this figure indicates that there is a significant difference between results depending on Tukey's test. In turn, the letters of each color refer to their respective compound, orange for $\mathrm{C}$ and purple for DHC. Only the existence or not of a significant difference in the two major compounds has been indicated in Figure 3 for a better viewing. The results obtained for the three minor capsaicinoids (n-DHC, h-C, and h-DHC) are shown in detail in Figure S2 with a different scale.

\subsection{Evolution of the Standardized Values of Capsaicinoids}

The standardized evolution of the main "Naga Jolokia" pepper capsaicinoids can be observed in Table 2. These values were normalized with respect to the day of the greatest concentration of each compound; that is, all of them refer to $100 \%$ of their maximum content, which coincided in all of them at $33 \mathrm{dpa}$. It was observed that the evolution of the relative percentage throughout maturation followed the same above-explained trend.

Table 2. Relative percentages (\%) of individual capsaicinoids during "Naga Jolokia" pepper fruit development $(n=3)$.

\begin{tabular}{cccccc}
\hline Dpa & n-DHC & C & DHC & h-C & h-DHC \\
\hline 12 & 1.03 & 0.48 & 0.31 & 0.29 & 0.12 \\
19 & 27.59 & 24.04 & 25.83 & 46.03 & 16.88 \\
26 & 62.01 & 48.44 & 51.38 & 71.82 & 59.82 \\
33 & 100.00 & 100.00 & 100.00 & 100.00 & 100.00 \\
40 & 3.65 & 3.90 & 3.56 & 3.83 & 0.00 \\
47 & 50.96 & 34.55 & 33.71 & 37.83 & 37.97 \\
54 & 30.34 & 26.89 & 19.79 & 25.32 & 31.55 \\
61 & 19.46 & 20.25 & 15.02 & 20.22 & 16.92 \\
\hline
\end{tabular}

It is noteworthy that all the capsaicinoids followed the same pattern throughout maturation. However, this did not occur in other pepper cultivars reported in the literature. For example, in "Cayenne" pepper, the relative percentages of n-DHC, DHC, h-C, and h-DHC followed the same 
pattern. They increased until $40 \mathrm{dpa}$, when they reached their maximum concentration in the fruit development process. Then, there was a gradual decrease until $80 \mathrm{dpa}$ with a minimum level between $42 \%$ and $52 \%$ of maximum content. However, $\mathrm{C}$ presented a different behavior. Thus, the maximum relative percentage was reached on $20 \mathrm{dpa}$, much earlier than the others [23]. In the case of "Peter" pepper, $\mathrm{C}, \mathrm{h}-\mathrm{DHC}$, and DHC showed the same linear pattern, while h-C and n-DHC presented a different trend [25].

In this sense, it would be necessary to monitor every detail of the cultivation conditions of each crop, as well as the rest of the environmental factors, since they may greatly influence the final product and its composition [48]. If these parameters are perfectly controlled and described, the results should be reproducible and comparable to those obtained by other researchers.

\subsection{Evolution of Capsiate Content}

As explained before for capsaicinoids, capsiate was identified with the UHPLC-Q-ToF-MS system and quantified with the rp-UHPLC-PDA system. Figure 4 shows the evolution of capsiate during the maturation of the peppers. Capsiate accumulation reached its maximum value at $19 \mathrm{dpa}$. Subsequently, the capsiate content decreased significantly, corresponding to approximately $70 \%$ of its maximum content. Such reduction could be associated with a decrease in the expression of the biosynthetic structural genes of capsinoids or, alternatively, to the activities of different peroxidases, as described for capsaicinoids [49]. Two main peroxidase isoenzyme groups can be distinguished in Capsicum by their individual isoelectric points. The first main group is composed of acidic isoelectric point peroxidase isoenzymes called APrx, and the second group corresponds to basic isoelectric point peroxidase isoenzymes (BPrx) [29]. Basic peroxidases are found in cell walls and vacuoles, which are the hypothetical places for capsiate accumulation. The use of different inhibitors allowed for confirmation of the nature of this peroxidase for the detected activity. These results strongly support the role of the basic peroxidases of $C$. annuum as being responsible for capsiate oxidation [50]. Over several subsequent days, the capsiate content remained practically constant. Tanaka et al. [51] claimed that "CH-19 Sweet" content increased between 10 and $30 \mathrm{dpa}$ and then decreased to around $58 \%$ of its maximum level. This decrease in content took place slightly later than did in our study.

0.4

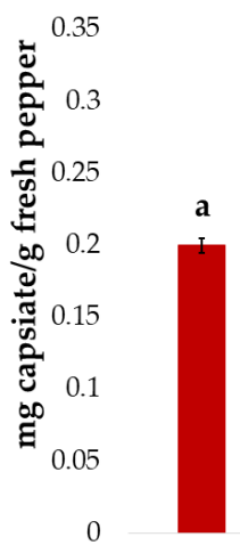

12

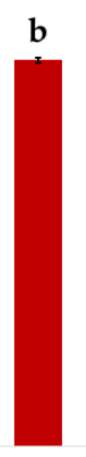

19

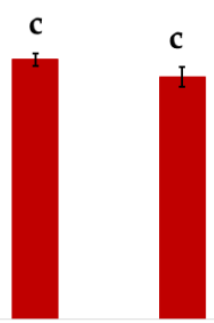

26

\section{Capsiate}

Days post-anthesis (dpa)

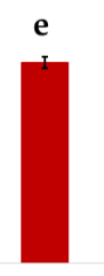

47

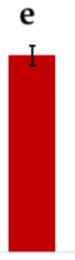

54

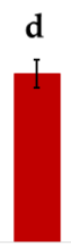

61

Figure 4. Evolution of capsiate content $\left(\mathrm{mg} \mathrm{g}^{-1}\right.$ of FW) during "Naga Jolokia" pepper fruit development $(n=3)$. According to the Tukey's test, results with a $p$-value less than 0.05 were considered to be statistically different. Taking this into account, the use of different letters in this figure indicates that there is a significant difference between results depending on Tukey's test. 
Capsinoids, which are esters of fatty acid and vanillyl alcohol, are stable in nonpolar solvents such as ethyl acetate but decompose easily in polar solvents, such as water, methanol, and so forth [52]. This instability in water can also be responsible for the rapid decrease of capsinoid contents in pepper fruits. Capsinoids are also unstable in water and at high temperatures, which is why their content may decrease during fruit ripening. Therefore, fruits containing capsinoids should be consumed raw and before full maturation [53].

In order to obtain a high level of capsinoids, mature green fruits should be collected approximately at $19 \mathrm{dpa}$, when the capsiate content reaches it maximum level. Similar trends to accumulate capsinoids during fruit ripening have been observed in several Capsicum cultivars at different levels of pungency [54,55].

\section{Conclusions}

The behavior of capsaicinoids present in "Naga Jolokia" peppers during the ripening process differed from previous reports regarding other Capsicum cultivars. Capsaicin is the major capsaicinoid and its proportion with respect to the rest of the individual capsaicinoids did not vary with the fruit ripening state. Once the capsaicinoids reached their maximum concentration at $33 \mathrm{dpa}$, it dropped drastically (by $96.35 \%$ ). Such a decrease is somewhat advanced with respect to what has been described in the literature and could be attributed to this variety's own genetic factors or to specific growing conditions. This study intends to contribute to establishing appropriate harvesting techniques to obtain pungent peppers. It has been proved that the ripening stage is essential to determine the ideal time for harvesting, since drastic changes in capsaicinoid content have been observed over the ripening period. This is of great interest since one of the most sought-after attributes in peppers, and particularly in the cultivar "Naga Jolokia", is the content of pungent compounds that confer to it its highly spicy character. Given the important biological activity of capsaicinoids and capsinoids, the information described here allows the harvesting of "Naga Jolokia" peppers at the moment when their content is at its maximum value. The optimal time for the collection of peppers, depending on their pungent characteristics, would be when they have their highest capsaicinoid content, due to the aforementioned excellent biological properties of these compounds. Based on the results obtained in this research, the optimal time would be at 33 dpa. Furthermore, harvesting should be carried out before the over-ripening stages of the fruit have been visibly reached. In any case, choosing the right moment to harvest this fruit should always be taken into account while bearing in mind that substantial variations in their total capsaicinoid content depending on the harvesting time are to be expected. With respect to the capsiate content, the maximum is reached in the first weeks of maturation, after which a moderate drop in its concentration is observed.

Supplementary Materials: The following are available online at http://www.mdpi.com/2073-4395/10/2/252/s1. Table S1. Chromatographic and $\mathrm{m} / \mathrm{z}$ parameters of capsaicinoids and capsiate for the UHPLC-QToF-MS method. Table S2. Chromatographic parameters of capsaicinoids and capsiate for the UHPLC-DAD method. Figure S1. Individual Capsaicinoids. Figure S2. Individual Capsaicinoids Percentages.

Author Contributions: Conceptualization, G.F.B. and A.G.-C.; methodology, M.V.-E. and J.A.O.-R.; software, M.F.-G.; formal analysis, M.V.-E., O.F., and A.V.G.-d.-P.; investigation, M.V.-E. and J.A.O.-R.; resources, M.P., A.G.-C., and C.G.B.; data curation, M.F.-G., E.E.-B., and O.F.; writing-original draft preparation, M.V.-E. and J.A.O.-R.; writing-review and editing, G.F.B., E.E.-B., and O.F.; supervision, G.F.B., M.F.-G., and E.E.-B.; project administration, A.G.-C. and G.F.B.; funding acquisition, A.G.-C. and C.G.B. All authors have read and agreed to the published version of the manuscript.

Funding: This work is part of the RTA2015-00042-C02-01 project funded by the National Institute for Agriculture and Food Research and Technology (INIA) and cofinanced by the European Fund for Regional Development (FEDER). It was also supported by A11-17R and V. la Andaluza and University of Cadiz by the project OT2016/046. The authors thank the Spanish Ministry of Education, Culture, and Sport for the predoctoral contract (FPU17-02962) granted to Mercedes Vázquez-Espinosa.

Acknowledgments: The authors are grateful to the Instituto de Investigación Vitivinícola y Agroalimentaria (IVAGRO) for providing the necessary facilities to carry out the research.

Conflicts of Interest: The authors declare no conflict of interest. 


\section{Abbreviations}

$\begin{array}{ll}\text { C } & \text { Capsaicin } \\ \text { CITA } & \text { Agri-Food Research and Technology Center } \\ \text { CTE } & \text { Capsiate } \\ \text { DHC } & \text { Dihydrocapsaicin } \\ \text { DHCTE } & \text { Dihydrocapsiate } \\ \text { Dpa } & \text { Days postanthesis } \\ \text { FW } & \text { Fresh weight } \\ \text { h-C } & \text { Homocapsaicin } \\ \text { h-DHC } & \text { Homodihydrocapsaicin } \\ \text { n-DHC } & \text { Nordihydrocapsaicin } \\ \text { n-DHCTE } & \text { Nordihydrocapsiate } \\ \text { PDA } & \text { Photodiode array detector } \\ \text { QToF-MS } & \text { Quadrupole-time-of-flight mass spectrometry } \\ \text { rp-HPLC } & \text { Reverse-phase high-performance liquid chromatography } \\ \text { rp-UHPLC: } & \text { Reverse-phase ultra-high-performance liquid chromatography } \\ \text { SHUs } & \text { Scoville Heat Units } \\ \text { UAE } & \text { Ultrasound-assisted extraction }\end{array}$

\section{References}

1. Chiaiese, P.; Corrado, G.; Minutolo, M.; Barone, A.; Errico, A. Transcriptional regulation of ascorbic acid during fruit ripening in pepper (Capsicum annuum) varieties with low and high antioxidants content. Plants 2019, 8, 206. [CrossRef] [PubMed]

2. Ananthan, R.; Subhash, K.; Longvah, T. Capsaicinoids, amino acid and fatty acid profiles in different fruit components of the world hottest Naga king chilli (Capsicum chinense Jacq). Food Chem. 2018, 238, 51-57. [CrossRef]

3. Penagos-Calvete, D.; Guauque-Medina, J.; Villegas-Torres, M.F.; Montoya, G. Analysis of triacylglycerides, carotenoids and capsaicinoids as disposable molecules from Capsicum agroindustry. Hortic. Environ. Biotechnol. 2019, 60, 227-238. [CrossRef]

4. Dias, A.L.B.; Arroio Sergio, C.S.; Santos, P.; Barbero, G.F.; Rezende, C.A.; Martínez, J. Ultrasound-assisted extraction of bioactive compounds from dedo de moça pepper (Capsicum baccatum L.): Effects on the vegetable matrix and mathematical modeling. J. Food Eng. 2017, 198, 36-44. [CrossRef]

5. Barbero, G.F.; Liazid, A.; Azaroual, L.; Palma, M.; Barroso, C.G. Capsaicinoid contents in peppers and pepper-related spicy foods. Int. J. Food Prop. 2016, 19, 485-493. [CrossRef]

6. De Aguiar, A.C.; Sales Silva, L.P.; de Rezende, C.A.; Barbero, G.F.; Martínez, J. Encapsulation of pepper oleoresin by supercritical fluid extraction of emulsions. J. Supercrit. Fluids 2016, 112, 37-43. [CrossRef]

7. Hervert-Hernández, D.; Sáyago-Ayerdi, S.G.; Goñi, I. Bioactive compounds of four hot pepper varieties (Capsicum annuum L.), antioxidant capacity, and intestinal bioaccessibility. J. Agric. Food Chem. 2010, 58, 3399-3406. [CrossRef]

8. Thán, M.; Németh, J.; Szilvássy, Z.; Pintér, E.; Helyes, Z.; Szolcsányi, J. Systemic anti-inflammatory effect of somatostatin released from capsaicin-sensitive vagal and sciatic sensory fibres of the rat and guinea-pig. Eur. J. Pharmacol. 2000, 399, 251-258. [CrossRef]

9. Smith, H.; Brooks, J.R. Capsaicin-based therapies for pain control. Prog. Drug Res. 2014, 68, 129-146.

10. Molina-Torres, J.; Garcia-Chavez, A.; Ramirez-Chavez, E. Antimicrobial properties of alkamides present in flavouring plants traditionally used in Mesoamerica: Affinin and capsaicin. J. Ethnopharmacol. 1999, 64, 241-248. [CrossRef]

11. Bley, K.; Boorman, G.; Mohammad, B.; McKenzie, D.; Babbar, S. A comprehensive review of the carcinogenic and anticarcinogenic potential of capsaicin. Toxicol. Pathol. 2012, 40, 847-873. [CrossRef] [PubMed]

12. Joo, J.I.; Kim, D.H.; Choi, J.W.; Yun, J.W. Proteomic analysis for antiobesity potential of capsaicin on white adipose tissue in rats fed with a high fat diet. J. Proteome Res. 2010, 9, 2977-2987. [CrossRef] [PubMed]

13. Luo, X.J.; Peng, J.; Li, Y.J. Recent advances in the study on capsaicinoids and capsinoids. Eur. J. Pharmacol. 2011, 650, 1-7. [CrossRef] [PubMed] 
14. Yazawa, S.; Suetome, N.; Okamoto, K.; Namiki, T. Content of capsaicinoids and capsaicinoid-like substances in fruit of pepper (Capsicum annuum L.) hybrids made with 'CH-19 Sweet' as a parent. J. Jpn. Soc. Hortic. Sci. 1989, 58, 601-607. [CrossRef]

15. Fayos, O.; Savirón, M.; Orduna, J.; Barbero, G.F.; Mallor, C.; Garcés-Claver, A. Quantitation of capsiate and dihydrocapsiate and tentative identification of minor capsinoids in pepper fruits (Capsicum spp.) by HPLC-ESI-MS/MS (QTOF). Food Chem. 2019, 270, 264-272. [CrossRef]

16. Swint, J.M.; Beining, K.M.; Bryant, J.A.; Tucker, R.M.; Ludy, M.J. Comparison of Capsaicin and Capsiate's Effects at a Meal. Chemosens. Percept. 2015, 8, 174-182. [CrossRef]

17. Sutoh, K.; Kobata, K.; Yazawa, S.; Watanabe, T. Capsinoid is biosynthesized from phenylalanine and valine in a non-pungent pepper, Capsicum annuum L. cv. CH-19 Sweet. Biosci. Biotechnol. Biochem. 2006, 70, 1513-1516. [CrossRef]

18. Islam, M.A.; Sharma, S.S.; Sinha, P.; Negi, M.S.; Neog, B.; Tripathi, S.B. Variability in capsaicinoid content in different landraces of Capsicum cultivated in north-eastern India. Sci. Hortic. 2015, 183, 66-71. [CrossRef]

19. Barbero, G.F.; Molinillo, J.M.G.; Varela, R.M.; Palma, M.; Macías, F.A.; Barroso, C.G. Application of Hansch's Model to capsaicinoids and capsinoids: A study using the quantitative structure-Activity relationship. A novel method for the synthesis of capsinoids. J. Agric. Food Chem. 2010, 58, 3342-3349. [CrossRef]

20. Barbero, G.F.; Molinillo, J.M.G.; Varela, R.M.; Palma, M.; Macías, F.A.; Barroso, C.G. Method for the Chemical Synthesis of Capsinoids. U.S. Patent 20100256413A1, 2010.

21. De Aguiar, A.C.; Coutinho, J.P.; Barbero, G.F.; Godoy, H.T.; Martínez, J. Comparative study of capsaicinoid composition in Capsicum Peppers grown in Brazil. Int. J. Food Prop. 2016, 19, 1292-1302. [CrossRef]

22. Giuffrida, D.; Dugo, P.; Torre, G.; Bignardi, C.; Cavazza, A.; Corradini, C.; Dugo, G. Characterization of 12 Capsicum varieties by evaluation of their carotenoid profile and pungency determination. Food Chem. 2013, 140, 794-802. [CrossRef] [PubMed]

23. Jeeatid, N.; Techawongstien, S.; Suriharn, B.; Chanthai, S.; Bosland, P.W.; Techawongstien, S. Influence of water stresses on capsaicinoid production in hot pepper (Capsicum chinense Jacq.) cultivars with different pungency levels. Food Chem. 2018, 245, 792-797. [CrossRef] [PubMed]

24. Barbero, G.F.; Ruiz, A.G.; Liazid, A.; Palma, M.; Vera, J.C.; Barroso, C.G. Evolution of total and individual capsaicinoids in peppers during ripening of the Cayenne pepper plant (Capsicum annuum L.). Food Chem. 2014, 153, 200-206. [CrossRef]

25. Contreras-Padilla, M.; Yahia, E.M. Changes in capsaicinoids during development, maturation, and senescence of Chile Peppers and relation with peroxidase activity. J. Agric. Food Chem. 1998, 46, 2075-2079. [CrossRef]

26. Barbero, G.F.; de Aguiar, A.C.; Carrera, C.; Olachea, Á.; Ferreiro-González, M.; Martínez, J.; Palma, M.; Barroso, C.G. Evolution of capsaicinoids in Peter Pepper (Capsicum annuum var. annuum) during fruit ripening. Chem. Biodiver. 2016, 13, 1068-1075. [CrossRef]

27. Fayos, O.; de Aguiar, A.C.; Jiménez-Cantizano, A.; Ferreiro-González, M.; Garcés-Claver, A.; Martínez, J.; Mallor, C.; Ruiz-Rodríguez, A.; Palma, M.; Barroso, C.G.; et al. Ontogenetic variation of individual and total capsaicinoids in Malagueta peppers (Capsicum frutescens) during fruit maturation. Molecules 2017, 22, 736. [CrossRef]

28. Boersch, A.; Callingham, B.A.; Lembeck, F.; Sharman, D.F. Enzymic oxidation of capsaicin. Biochem. Pharmacol. 1991, 41, 1863-1869. [CrossRef]

29. Bernal, M.A.; Calderón, A.A.; Pedreño, M.A.; Muñoz, R.; Barceló, A.R.; de Cáceres, F.M. Capsaicin oxidation by peroxidase from Capsicum annuum (Var. annuum) fruits. J. Agric. Food Chem. 1993, 41, 1041-1044. [CrossRef]

30. Lema, A.; Martinez, T.; Garcés, A.; Fayos, O.; Pomar, F.; González, S.; Silvar, C.; Mallor, C.; Barbero, G.F. Study of the oxidation of capsicinoids by basic peroxidases from pepper. In Proceedings of the XIV Spanish-Portuguese Congress of Plant Physiology, SEFV, Toledo, Spain, 14-17 June 2015; p. 188, ISBN 978-84-606-8883-9.

31. Moirangthem, S.S.; Gogoi, S.; Thongbam, P.D.; Ramya, K.T.; Fiyaz, R.A.; Pandey, D.S. Effect of sowing time and crop geometry on the Casaicinoid content in Bhoot Jolokia (Capsicum chinense Jacq.). J. Sci. Technol. 2014, 51, 1974-1981. [CrossRef]

32. Meghvansi, M.K.; Siddiqui, S.; Khan, M.H.; Gupta, V.K.; Vairale, M.G.; Gogoi, H.K.; Singh, L. Naga chilli: A potential source of capsaicinoids with broad-spectrum ethnopharmacological applications. J. Ethnopharmacol. 2010, 132, 1-14. [CrossRef] 
33. Purkayastha, J.; Alam, S.I.; Gogoi, H.K.; Singh, L.; Veer, V. Molecular characterization of 'Bhut Jolokia' the hottest chilli. J. Biosci. 2012, 37, 757-768. [CrossRef] [PubMed]

34. Dias, A.L.B.; Arroio Sergio, C.S.; Santos, P.; Barbero, G.F.; Rezende, C.A.; Martínez, J. Effect of ultrasound on the supercritical $\mathrm{CO}_{2}$ extraction of bioactive compounds from dedo de moça pepper (Capsicum baccatum. Var. pendulum). Ultrason. Sonochem. 2016, 31, 284-294. [CrossRef] [PubMed]

35. Coutinho, J.P.; Barbero, G.F.; Avellán, O.F.; Garcés-Claver, A.; Godoy, H.T.; Palma, M.; Barroso, C.G. Use of multivariate statistical techniques to optimize the separation of 17 capsinoids by ultra-performance liquid chromatography using different columns. Talanta 2015, 134, 256-263. [CrossRef] [PubMed]

36. Coutinho, J.P.; Barbero, G.F.; Godoy, H.T.; Palma, M.; Barroso, C.G. Multivariate optimization by statistical methods of ultra-high-performance liquid chromatography conditions for the separation of 17 capsaicinoids. Anal. Methods 2016, 8, 1659-1666. [CrossRef]

37. Barbero, G.F.; Liazid, A.; Palma, M.; Barroso, C.G. Ultrasound-assisted extraction of capsaicinoids from peppers. Talanta 2008, 75, 1332-1337. [CrossRef]

38. Vázquez-Espinosa, M.; González-de-Peredo, A.V.; Ferreiro-González, M.; Barroso, C.G.; Palma, M.; Barbero, G.F.; Espada-Bellido, E. Optimizing and comparing ultrasound- and microwave-assisted extraction methods applied to the extraction of antioxidant capsinoids in peppers. Agronomy 2019, 9, 633. [CrossRef]

39. Iwai, K.; Suzuki, T.; Fujiwake, H. Formation and accumulation of pungent principle of hot pepper fruits, capsaicin and its analogues, in Capsicum annuun var. annuun cv. Karayatsubusa at different growth stages after flowering. Agric. Biol. Chem. 1979, 43, 2493-2498. [CrossRef]

40. Menichini, F.; Tundis, R.; Bonesi, M.; Loizzo, M.R.; Conforti, F.; Statti, G.; de Cindio, B.; Houghton, P.J.; Menichini, F. The influence of fruit ripening on the phytochemical content and biological activity of Capsicum chinense Jacq. cv Habanero. Food Chem. 2009, 114, 553-560. [CrossRef]

41. Pino, J.; González, M.; Ceballos, L.; Centurión-Yah, A.R.; Trujillo-Aguirre, J.; Latournerie-Moreno, L.; Sauri-Duch, E. Characterization of total capsaicinoids, colour and volatile compounds of Habanero chilli pepper (Capsicum chinense Jack.) cultivars grown in Yucatan. Food Chem. 2007, 104, 1682-1686. [CrossRef]

42. Bosland, P.W.; Baral, J.B. 'Bhut Jolokia'-The world's hottest known chile pepper is a putative naturally occurring interspecific hybrid. HortScience 2007, 42, 222-224. [CrossRef]

43. Díaz, J.; Pomar, F.; Bernal, Á.; Merino, F. Peroxidases and the metabolism of capsaicin in Capsicum annuum L. Phytochem. Rev. 2004, 3, 141-157. [CrossRef]

44. Estrada, B.; Bernal, M.A.; Díaz, J.; Pomar, F.; Merino, F. Fruit development in Capsicum annuum: Changes in capsaicin, lignin, free phenolics, and peroxidase patterns. J. Agric. Food Chem. 2000, 48, 6234-6239. [CrossRef] [PubMed]

45. Olguín-Rojas, J.A.; Fayos, O.; Vázquez-León, L.A.; Ferreiro-González, M.; Rodríguez-Jimenes, G.C.; Palma, M.; Garcés-Claver, A.; Barbero, G.F. Progression of the total and individual capsaicinoids content in the fruits of three different cultivars of capsicum chinense Jacq. Agronomy 2019, 9, 141. [CrossRef]

46. Sganzerla, M.; Coutinho, J.P.; de Melo, A.M.T.; Godoy, H.T. Fast method for capsaicinoids analysis from Capsicum chinense fruits. Food Res. Int. 2014, 64, 718-725. [CrossRef]

47. Lavorgna, M.; Orlo, E.; Nugnes, R.; Piscitelli, C.; Russo, C.; Isidori, M. Capsaicin in hot chili peppers: In vitro evaluation of its antiradical, antiproliferative and apoptotic activities. Plant Foods Hum. Nutr. 2019, 74, 164-170. [CrossRef] [PubMed]

48. Harvell, K.P.; Bosland, P.W. The environment produces a significant effect on pungency of chiles. HortScience 1997, 32, 1292. [CrossRef]

49. Fayos, O.; Ochoa-Alejo, N.; de la Vega, O.M.; Savirón, M.; Orduna, J.; Mallor, C.; Barbero, G.F.; Garcés-Claver, A. Assessment of capsaicinoid and capsinoid accumulation patterns during fruit development in three chili pepper genotypes (Capsicum spp.) carrying pun1 and pAMT alleles related to pungency. J. Agric. Food Chem. 2019, 67, 12219-12227. [CrossRef] [PubMed]

50. Lema, A.; Martínez-Cortés, T.; Garcés, A.; Mallor, C.; Fayos, O.; Barbero, G.F.; Silvar, C.; Pomar, F. 5-5’ dicapsiate: Product of the oxidation of capsiate by cationic peroxidases from pepper (Capsicum annuum L.). In Proceedings of the XVIth EUCARPIA Capsicum and Eggplant Working Group Meeting in memoriam Dr. Alain Palloix, Kecskemet, Hungary, 12-14 September 2016; pp. 500-505, ISBN 978-615-5270-27-7. [CrossRef]

51. Tanaka, Y.; Hosokawa, M.; Otsu, K.; Watanabe, T.; Yazawa, S. Assessment of capsiconinoid composition, nonpungent capsaicinoid analogues, in Capsicum cultivars. J. Agric. Food Chem. 2009, 57, 5407-5412. [CrossRef] [PubMed] 
52. Sutoh, K.; Kobata, K.; Watanabe, T. Stability of capsinoid in various solvents. J. Agric. Food Chem. 2001, 49, 4026-4030. [CrossRef] [PubMed]

53. Tanaka, Y.; Yoneda, H.; Hosokawa, M.; Miwa, T.; Yazawa, S. Application of marker-assisted selection in breeding of a new fresh pepper cultivar (Capsicum annuum) containing capsinoids, low-pungent capsaicinoid analogs. Sci. Hortic. 2014, 165, 242-245. [CrossRef]

54. Jang, S.; Han, K.; Jo, Y.D.; Jeong, H.-J.; Siddiqui, M.I.; Kang, B.-C. Substitution of a dysfunctional pAMT allele results in low-pungency but high levels of capsinoid in Capsicum chinense 'Habanero'. Plant Breed. Biotechnol. 2015, 3, 119-128. [CrossRef]

55. Jarret, R.L.; Bolton, J.; Perkins, L.B. 509-45-1, a Capsicum annuum pepper germplasm containing high concentrations of capsinoids. HortScience 2014, 49, 107-108. [CrossRef]

(C) 2020 by the authors. Licensee MDPI, Basel, Switzerland. This article is an open access article distributed under the terms and conditions of the Creative Commons Attribution (CC BY) license (http://creativecommons.org/licenses/by/4.0/). 